\title{
BLICKDIAGNOSE
}

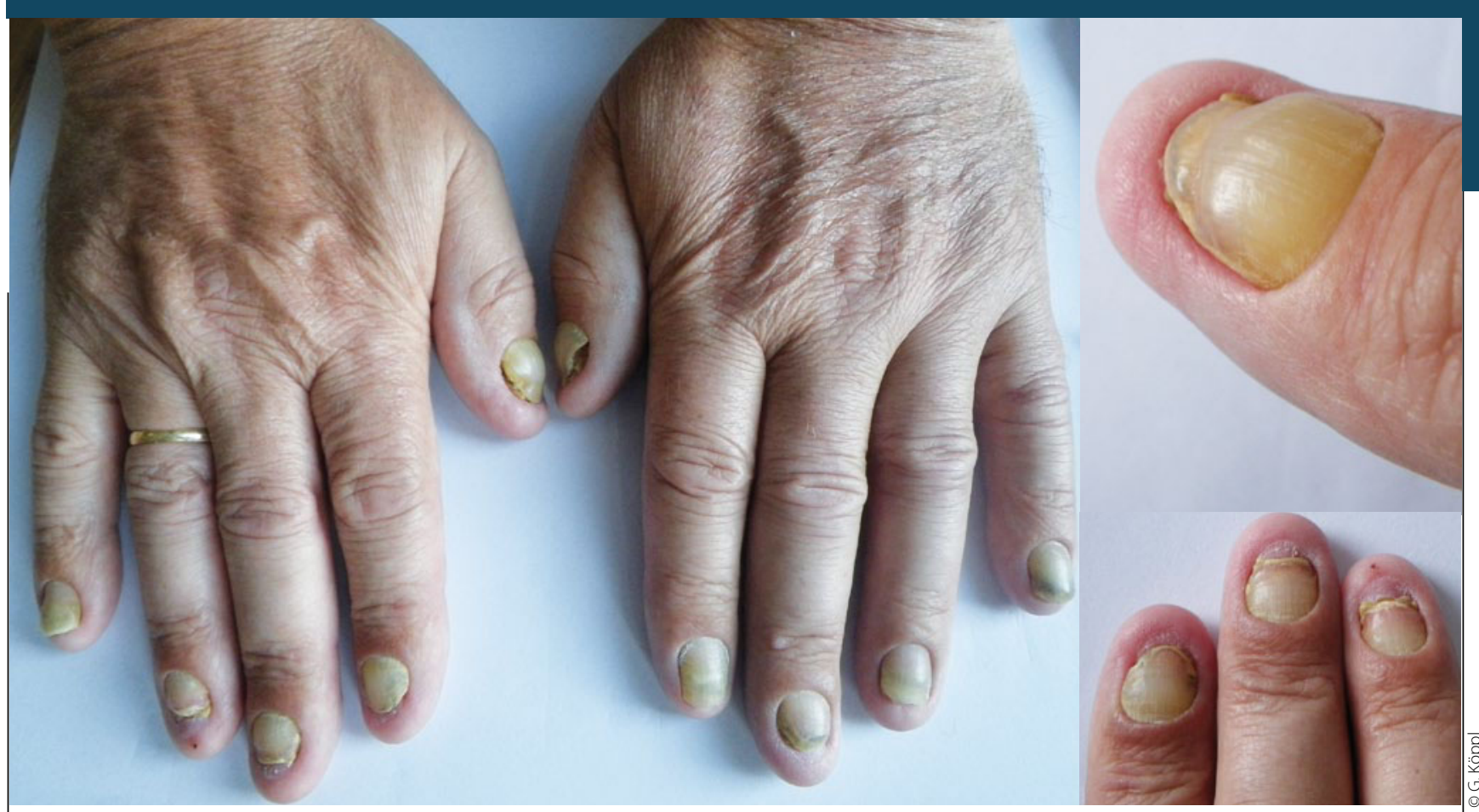

Pilze sind es nicht

\section{Was macht die Nägel so kaputt?}

— Der jetzt 55-jährige Schiffbauingenieur stellte sich zuerst mit brüchigen, gelblich-bräunlich verfärbten Nägeln vor. Alle Finger- und Zehennägel waren betroffen.

Pilzkulturen bleiben ohne Wachstum. Die Probeexzision vom Nagelbett zeigte ein Bild wie bei einer mechanischen Onycholyse. Das Labor war bis auf die diskret erhöhte Harnsäure zunächst unauffällig. Der Patient ist Pfeifenraucher. Das Röntgenbild der Lunge zeigte eine diskret verstärkte Lungenzeichnung im linken Unterlappen wie bei Bronchiolitis.

Im weiteren Verlauf bildeten sich schmerzlose Elephantiasis-artige Schwellungen der Unterschenkel. Das Gesamteiweiß war jetzt mit 4,4 g/dl deutlich erniedrigt bei unauffälliger Serumprotein-Elektrophorese. Nach weiteren zwei Jahren kam es zu Gewichtsabnahme und Kurzatmigkeit. Das Röntgenbild des Thorax zeigte jetzt einen massiven beidseitigen Pleuraerguss mit diskretem Perikarderguss.
Diagnose: „Yellow-nail-Syndrom"

Keywords: yellow nail syndrome, pleural effusion, pericardial effusion

- Dr.med. Gottfried Köppl MPH, Facharzt für Allgemeinmedizin, Große Straße 77, D-24937 Flensburg

\section{Weitere Infos auf springermedizin.de}

Weitere Blickdiagnosen finden Sie im Internet unter: - http://www.springermedizin.de/blickdiagnose 